
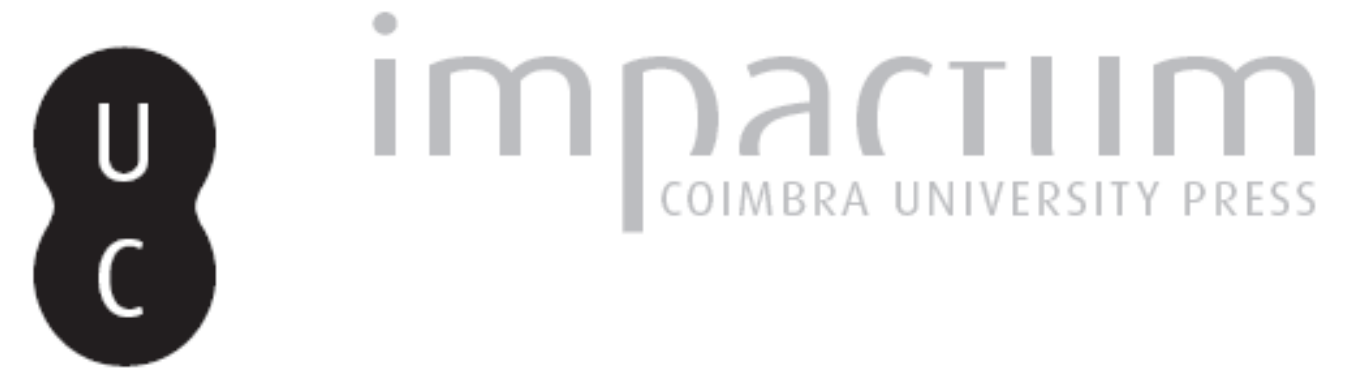

Governança da Educação Superior: contextos e processos de mudança em Portugal

Autor(es): $\quad$ Pedrosa, Júlio; Santos, Hália Costa; Mano, Margarida; Gaspar, Teresa

Publicado por: Fórum de Gestão do Ensino Superior nos Países e Regiões de Língua

URL

persistente:

URI:http://hdl.handle.net/10316.2/36219

DOI:

DOI:http://dx.doi.org/10.14195/2183-2722_1-1_4

Accessed : $\quad$ 26-Apr-2023 11:47:10

A navegação consulta e descarregamento dos títulos inseridos nas Bibliotecas Digitais UC Digitalis, UC Pombalina e UC Impactum, pressupõem a aceitação plena e sem reservas dos Termos e Condições de Uso destas Bibliotecas Digitais, disponíveis em https://digitalis.uc.pt/pt-pt/termos.

Conforme exposto nos referidos Termos e Condições de Uso, o descarregamento de títulos de acesso restrito requer uma licença válida de autorização devendo o utilizador aceder ao(s) documento(s) a partir de um endereço de IP da instituição detentora da supramencionada licença.

Ao utilizador é apenas permitido o descarregamento para uso pessoal, pelo que o emprego do(s) título(s) descarregado(s) para outro fim, designadamente comercial, carece de autorização do respetivo autor ou editor da obra.

Na medida em que todas as obras da UC Digitalis se encontram protegidas pelo Código do Direito de Autor e Direitos Conexos e demais legislação aplicável, toda a cópia, parcial ou total, deste documento, nos casos em que é legalmente admitida, deverá conter ou fazer-se acompanhar por este aviso.

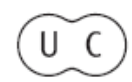




\section{REVISTA}
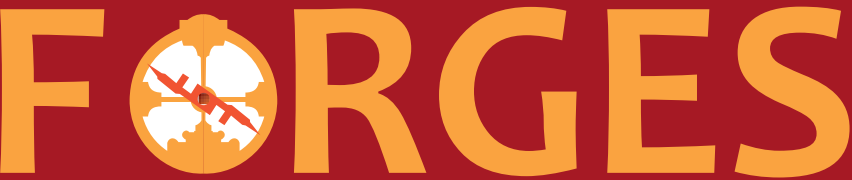

Fórum da Gestão do Ensino Superior nos Países e Regiões de Língua Portuguesa

Ensino Superior

Organizadores

Sônia Fonseca | Luísa Cerdeira |

Tomás Patrocínio
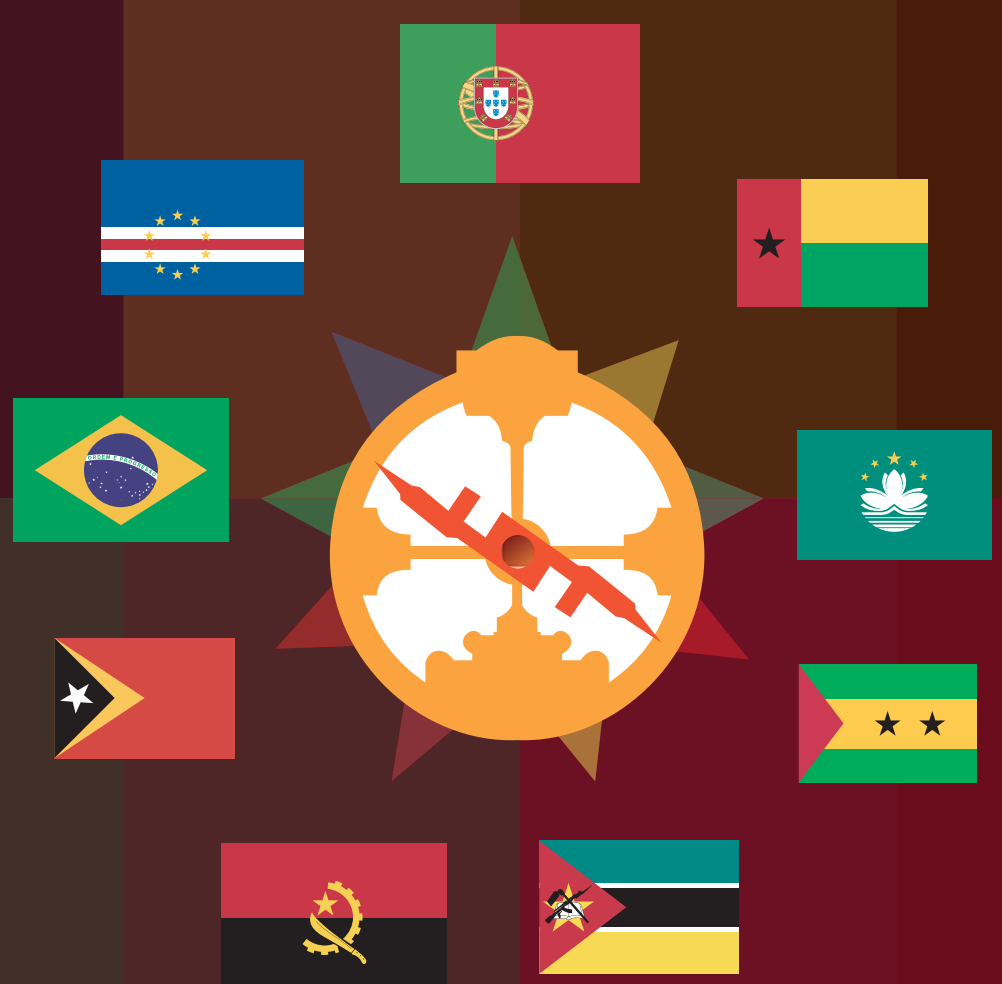
4

\title{
Governança da Educação Superior - contextos e processos de mudança em Portugal
}

\author{
Júlio Pedrosa ${ }^{1}$ \\ Hália Costa Santos ${ }^{2}$ \\ Margarida Mano $^{3}$ \\ Teresa Gaspar ${ }^{4}$
}

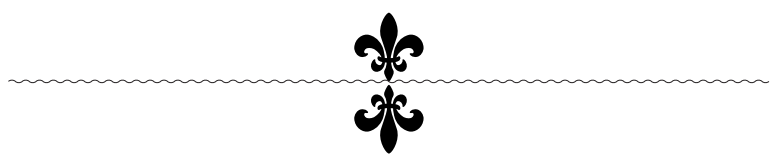

Resumo: O conceito de governança que se adoptará é o que foi usado recentemente num estudo promovido pela OCDE (Santiago, et al, 2008), significando "estruturas, relações e processos através dos quais as políticas para a educação superior são desenvolvidas, aplicadas e revistas, tanto a nível nacional como institucional". Apresenta-se, de seguida, uma análise dos fins que hoje são visados na Educação Superior e que sustentam a tendência observada para diversificar as ofertas. Um olhar sobre os sistemas que se desenvolveram em vários países (Amaral et al, 2002; Stevens, 2004; Fielden, 2008; Eurydice, 2012) permitirá identificar desafios à governança da Educação Superior que têm a ver com as redes e com as instituições que se consolidaram em vários contextos nas últimas décadas.

Portugal seguiu caminhos que se enquadram nestas tendências, apresentando hoje um sistema que inclui instituições de natureza politécnica e instituições de natureza universitária, o qual dispõe de um enquadramento à gestão e governança definido pela Constituição da República e por legislação específica aprovada em 2007. Olharemos o panorama observado em Portugal apresentando o modelo de governança consagrado no Regime Jurídico das Instituições de Ensino Superior (RJIES), instituído pela Lei n. ${ }^{\circ}$ 62/2007, de 10 de Setembro. Será em relação a este último que incluiremos

1 Universidade de Aveiro, Portugal.

2 Instituto Politécnico de Tomar, Portugal.

3 Universidade de Coimbra, Portugal.

4 Conselho Nacional de educação de Portugal. 
mais detalhe com apresentação e discussão da avaliação que recentemente fizémos da experiência colhida com este modo de governança institucional (CNE, 2013). Este estudo, realizado a solicitação do Conselho Nacional de Educação de Portugal, enquadra a mudança que aconteceu no País numa tendência observada em vários países europeus (Áustria, Dinamarca, Finlândia, Holanda, Reino Unido) no período em que se preparou e concretizou a alteração na legislação portuguesa.

O actual modelo de governança das instituições de Educação Superior adoptado em Portugal assenta na atribuição da responsabilidade da governança estratégica institucional a um Conselho Geral de constituição mista (membros eleitos pela comunidade académica e membros externos cooptados por aqueles membros eleitos). Este órgão elege o/a reitor/a, podendo as instituições, se o desejarem, instituir órgãos colegiais do tipo Senado. Referir-se-á, em síntese, os pontos de vista dos Presidentes dos Conselhos Gerais, recolhidos em entrevistas, sobre a adequação do modelo de governança aos seus fins, bem como a suas propostas de melhoria à luz da experiência vivida.

\section{Introdução}

O termo governança tem vindo a ser utilizado crescentemente no contexto da Educação Superior com significados que podem variar com autores e contextos (Fielden, 2008). Usaremos aquela palavra com o sentido que lhe foi atribuído num estudo recente da OCDE, onde é analisada a questão da governança da Educação Superior num alargado leque de contextos, significando "estruturas, relações e processos através dos quais as politicas para a educação superior são desenvolvidas, aplicadas e revistas, tanto a nível nacional como institucional" (Santiago, et al, 2008).

A discussão de modelos de governança requere uma análise prévia dos fins que são visados pelos sistemas de Educação Superior e pela ideia de Universidade nos dias que correm (Sousa Santos e Almeida Filho, 2011; Seabra Santos e Almeida Filho, 2012, Kerr, 2001; Graham, 2002; Clark, 1998). Este enquadramento permitirá compreender a dimensão da governança da Educação Superior que tem a ver com as redes de instituições e com os sistemas que se consolidaram em vários países europeus nas últimas décadas (Shindler, 2011; Eurybase, 2009, 2010). De facto, a dimensão da governança institucional da Educação Superior tem, naturalmente, que ser ana- 
lisada e discutida à luz das tendências e mudanças observadas em contextos de generalizada diversificação e diferenciação das missões das instituições e dos sistemas. Portugal seguiu caminhos que se enquadram nestas tendências (Teixeira et al, 2012) e apresenta hoje um sistema que inclui instituições de natureza politécnica e instituições de natureza universitária a quem cabem missões diferentes estabelecidas na legislação enquadradora.

De seguida teremos como foco a governança institucional, prestando especial atenção à autonomia (Christensen, 2011, Pedrosa, 2014) e aos modelos em uso e desenvolvimento na Europa e em Portugal (CNE, 2013). No caso português, está em causa o modelo de governança consagrado no Regime Jurídico das Instituições de Ensino Superior (RJIES), instituído pela Lei n.․․ 62/2007, de 10 de Setembro. As opções tomadas em Portugal seguem de perto a transformação nos modelos de governança institucional observada na Europa na primeira década deste século.

Apresenta-se, a finalizar, uma síntese da avaliação da experiência observada em Portugal com aquele modo de governança institucional (Pedrosa, Santos, Mano e Gaspar, 2013). Este estudo, realizado a solicitação do Conselho Nacional de Educação de Portugal, enquadra a mudança observada no País numa tendência registada em vários países europeus (Áustria, Dinamarca, Finlândia, Holanda, Reino Unido) no período em que se preparou e concretizou a alteração na legislação portuguesa. O actual modelo de governança das instituições de Educação Superior adoptado em Portugal assenta na atribuição da responsabilidade da governança estratégica institucional a um Conselho Geral de constituição mista (membros eleitos pela comunidade académica e membros externos cooptados por aqueles). Este órgão elege o/a reitor/a ou presidente, podendo as instituições, se o desejarem, instituir órgãos colegiais do tipo Senado. Daquele estudo retira-se uma síntese da análise feita aos pontos de vista dos Presidentes dos Conselhos Gerais sobre a adequação do modelo de governança aos seus fins, bem como as suas propostas de melhoria à luz da experiência vivida. 


\section{Os Fins da Educação Superior: Diversificação e Diferenciação das Ofertas}

A análise da problemática da governança da Educação Superior requere que se tenham bem presentes as respostas dadas a algumas perguntas: para que serve a Educação Superior? Qual é a natureza e quais são os propósitos fundamentais das organizações que se entregam a actividades incluídas neste sector educativo? Que redes e modos de oferta existem hoje e que desenvolvimentos se podem antever?

Uma forma de identificar respostas dadas àquelas questões, em distintos contextos, pode ser encontrada na análise dos perfis das instituições que hoje integram as redes de ofertas que se observam em variados países (Neves, 2003; Wadsack and Kasparovsky,2004; Marginson et al, 2008; Reimer and Jacob, 2011; Varghese and Martin, 2013). Este exercício, associado a uma cuidada análise do desenvolvimento da ideia de universidade (Shattock, 1966; Clark, 1998; Steven, 2004; Seabra Santos e Almeida Filho 2012; Kerr, 2001; Graham, 2002; Torgal, 2002; Reading, 2003; Sousa Santos e Almeida Filho, 2009) levou-nos a considerar, neste contexto, os seguintes fins da Educação Superior:

- A educação superior conducente a um grau (licenciado ou bacharel, mestre e doutor), dirigida normalmente a jovens que concluíram os seus estudos secundários na idade normal para essa formação;

- A educação superior de curta duração (normalmente 2 anos), conferindo diploma, mas não grau superior, dirigida a jovens em idade normal de prosseguir estudos superiores e a adultos durante o período de vida activa ou após tal período;

- A formação ao longo da vida para o exercício de actividades profissionais, de diversificada duração e formato, centrada sobre o saber fazer, daqueles diversos grupos de destinatários;

- O estudo avançado, erudito e a salvaguarda do saber adquirido pela Humanidade em condições que garantam a liberdade e a independência no questionamento, na pesquisa e na busca de saber. 
- A ampliação dos limites do conhecimento pela investigação científica autónoma, livre, orientada pelo bem comum;

- O desenvolvimento das comunidades humanas e a preservação do Universo, através do envolvimento com a Sociedade, a partilha de saberes e a valorização cultural, social e económica da cultura e dos resultados da investigação científica (a designada $3^{\underline{a}}$ missão).

As origens do Ensino ou Educação Superior podem encontrar-se facilmente na Universidade da Idade Média (Torgal, 2002 e Graham, 2002). Porém, é fundamental buscar as suas raízes, também, nas respostas que corporações de variada natureza procuraram para as consequências da revolução industrial, na investigação que os estados adoptaram para recuperar de guerras, para desenvolver a agricultura, ou com o propósito de potenciar o equilíbrio social e a democracia (Edwards, 1982; Kerr, 2001, Metz, 2010; Sousa Santos e Almeida Filho, 2009). Enfim, as raízes da Educação Superior e da ideia de Universidade, os contextos históricos, culturais, económicos, sociais e políticos em que as instituições existiram e se desenvolveram estão presentes, naturalmente, nas realidades que conhecemos.

O século XIX é especialmente elucidativo desta influência do ambiente sobre as opções escolhidas para proporcionar Educação Superior e estimular o desenvolvimento do saber. Enquanto na GrãBretanha se mantinha a presença hegemónica das Universidades de Oxford e Cambridge, Newman lançava na Irlanda a sua ideia de Universidade e nas grandes cidades da Grã-Bretanha surgia a Educação Superior mais voltada para o saber fazer. Humboldt, pela mesma altura, criava na Universidade de Berlim um paradigma de instituição que influenciaria decididamente a universidade americana de investigação, mas não impedia que nos EUA, em 1856, fosse assinada a lei de doação de terras que impulsionaria decisivamente os projectos universitários dedicados ao desenvolvimento dos estados e regiões, da agricultura e da indústria. A França, pelo seu lado, adoptava uma via que retirava da universidade a missão de investigação e, em seu lugar, acentuava o papel de educação geral superior a par da formação profissional de alto nível em organizações distintas, de estatuto idêntico - as Grandes Escolas, para 
formar engenheiros, profissionais da Economia, do Comércio e da Administração Pública.

Enquanto isto acontecia, em Portugal existia uma única Universidade, a Universidade de Coimbra (Torgal, 2002), observando-se ensaios de criação, em Lisboa e no Porto, de escolas superiores com fins específicos, focadas em necessidades das forças armadas e de alguns sectores da economia. A década de 60 do século XX trouxe aos meios universitários perturbações e germes de transformações que tiveram desenvolvimentos muito variados. Uma importante área em que foram observadas mudanças significativas nesta década envolveu a natureza das instituições e conduziu à diversificação dos sistemas em vários países europeus. Assim, assistiu-se à criação de uma rede de Politécnicos no Reino Unido e de Institutos Universitários de Tecnologia em França. As Fachhochschulen surgiram, então, na Alemanha (Schindler and Reimer, 2011) e, no final da década, em Portugal, estruturavam-se as bases para o lançamento de uma rede de Institutos e Escolas Superiores Politécnicas (Arroteia, 2002; Teixeira et al, 2012).

Cerca de trinta anos depois, em 1992, no Reino Unido assiste-se à transformação dos Politécnicos em Universidades, admitindo-se, em alguns círculos, que se iria iniciar um movimento no sentido da unificação dos sistemas. Tal não veio a acontecer e, pelo contrário, observa-se que países onde não existia uma oferta dual se criam redes de instituições novas com missões focadas mais na educação profissional, com significativo envolvimento de actores empresariais e regionais na respectiva governança: na Holanda (Marginson et al, 2008) criam-se as Hogescholen, na Finlândia (Davies et al, 2009) nasce uma rede de Ammattikorkeakoulu e na Áustria (Wadsack and Kasparovsky, 2004) e Suíça lançam-se Fachhochschulen.

A abertura da Educação Superior a novos e diversificados públicos (Edwards, 1982) tem associada a questão da equidade no acesso e no sucesso das distintas populações. Esta questão foi recentemente analisada para um alargado leque de países e contextos (OCDE, 2008; Reiner and Jacob, 2011). Para além de uma adequada adequação da Educação Superior com as ofertas de educação Secundária, deve reconhecer-se que a diferenciação de missões específicas das instituições coloca questões novas quer ao nível da governança dos sistemas quer à governança de cada instituição. De facto, vimos assistindo 
a mudanças profundas no panorama da Educação Superior, com transformações nos perfis das instituições e das redes resultantes de consolidação de sistemas diferenciados, ao mesmo tempo que acontecem fusões de instituições universitárias e destas com centros e institutos de investigação (Danish University and Property Agency, 2009). O apelo à formação de consórcios e à racionalização dos sistemas está também presente e induziu já mudanças significativas em alguns países. Em Portugal, esta é matéria na agenda da ES, sendo significativa a recente fusão da Universidade de Lisboa com a Universidade Técnica de Lisboa.Pode dizer-se, em suma, que se requer das lideranças políticas e das instituições uma atenção redobrada aos impactos destas transformações e uma capacidade reforçada para fazer escolhas e assumir as suas consequências de se dispor hoje de redes com um leque diversificado de fins, nas ofertas de Educação Superior.

\section{Modelos de Governança: Contextos e Tendências}

A análise cuidada dos enquadramentos legislativos que presidiram a algumas mudanças observadas na Europa permite compreender melhor as tendências e transformações observadas nos modelos de governança e na consolidação de estratégias de reforço da autonomia institucional (Amaral et al 2002, ).

Na Áustria, a Lei das Universidades de 2002, confere às Universidades o estatuto jurídico de pessoa colectiva de direito público, reforça a autonomia institucional e diversifica as suas fontes de financiamento, na tutela do Ministério Federal da Ciência e Investigação (Eurybase, 2009). As instituições universitárias assumem a sua autonomia no quadro estabelecido por contractos de desempenho e orçamentos globais válidos por períodos de três. As Fachhochschulen, criadas em 1993, estão sujeitas a regulamentação própria dependente da natureza jurídica da entidade instituidora e têm um enfoque regional. Os programas de formação proporcionados por estas instituições dirigem-se a profissões específicas, sendo previamente acreditados por um Conselho de avaliação e acreditação, por um período máximo de cinco anos.

A Dinamarca é outro caso interessante, em que aconteceram 
significativas transformações na Educação Euperior, na década de 2000 (Danish Universities and Property Agency, 2009; Eurybase 2010). O sistema está actualmente organizado em ensino superior curto, ensino superior médio e ensino superior longo. O primeiro é oferecido realizado em dez academias profissionais (Erhversakademier), cujos cursos têm a duração de dois anos, o ensino superior médio é responsabilidade de oito colégios profissionais (Professionshøjskoler), a maioria deles associados a universidades, que atribuem o grau de professional bachelor. As oito universidades proporcionam ensino superior longo, com o ensino superior artístico entregue a 15 instituições, sob tutela do ministério da Cultura. A Lei das Universidades de 2007 atribui às universidades o estatuto de pessoa jurídica de direito público, em que se reforça a autonomia académica e de gestão de recursos, funcionando sob a tutela do Ministério da Ciência, Tecnologia e Inovação. Também neste país se instituiu a contratualização de objectivos estratégicos, recursos e actividades, em contractos de desenvolvimento, com a duração de três a quatro anos. O financiamento é baseado em fórmula que tem em conta uma avaliação dos resultados.

A Lei das Universidades em vigor na Finlândia foi aprovada em 2009 e considera as universidades como instituições independentes de direito público ou fundações de direito privado, com autonomia e liberdade de ensino e investigação (Eurybase, 2010). As instituições passam a celebrar contratos plurianuais com o Ministério da Educação, nos quais se fixam metas qualitativas e quantitativas e o modelo de monitorização e avaliação da sua concretização. Estes acordos são assinados pelo Presidente do Conselho da Universidade e pelo Reitor, sendo as instituições financiadas com uma dotação baseada numa fórmula a que se junta um fundo dependente do desempenho da universidade. A Finlândia dispõe ainda de instituições de natureza politécnica (Ammattikorkeakoulu). Os desenvolvimentos mais recentes têm conduzido à formação de consórcios entre politécnicos e universidades, tendo em vista o aumento da eficiência na gestão do sistema.

O sistema holandês de Educação Superior organiza-se em Universidades e em Instituições de Educação Superior Profissional, Hogescholen, dispondo de um modelo de governança que é apontado como exmplar na capacidade de adaptação a exigências da 
sociedade e mudanças de contexto (Marginson et al, 2008; Eurybase, 2009). A natureza dos graus que aquelas instituições conferem e os modelos de governança adoptados estão claramente estabelecidos, espelhando a opção por um modelo de diferenciação de missões.

O Reino Unido tem actualmente uma rede de ofertas de Educação Superior que decorre de legislação de 1992, The Further and Higher Education Act, (Eurybase, 2010), em que se unificou o sistema transformando em universidades todas as instituições politécnicas existentes na altura. A Escócia, Inglaterra e o País de Gales dispõem hoje de universidades anteriores a 1992, instituídas em "cartas reais", e universidades resultantes daquela legislação de 1992, resultantes da transformações de instituições politécnicas, que são muitas vezes designadas "novas universidades". Um relatório recente da Comissão de Presidentes de Universidades (CUC, 2009) apresenta-nos os modelos de governança em uso nos diversos contextos institucionais. O sistema do Reino Unido inclui também os chamados Further Education Colleges, com actividades dirigidas prioritariamente a públicos diversos, que não são, normalmente, visados pelas universidades.

As mudanças na legislação que enquadra a autonomia e a governança da Educação Superior em Portugal devem, pois, ser vistas e analisadas tendo presente aquele quadro de transformações observado na Europa, bem como desenvolvimentos que aconteceram em outras regiões do globo. John Fielden, em trabalho que tem o foco em países da Commonwealth, associa as mudanças na governança da Educação Superior ao crescimento e diversificação da oferta e ao modo como os governos valorizam o seu contributo para o desenvolvimento económico (Fielden, 2008). Este artigo, centrado sobre as formas como os estados planeiam e dirigem a Educação Superior, apresenta uma síntese de processos observados num alargado grupo de países: África do Sul, Bangladesh, Estados Unidos da América, Malásia, Nova Zelândia, Paquistão, Reino Unido, Tanzânia. O autor entende que as mudanças observadas resultam de se constatar que os modelos de controlo centralizado nos governos se mostraram insustentáveis, à medida que a complexidade dos sistemas cresceu e se acentuou a necessidade de os dotar de enquadramentos que assegurem a sua melhor gestão. Significativa é a constatação de que existe uma tendência dos países para mudarem de modelos de 
controlo para modelos de supervisão estatal.

Os estudos publicados pela OCDE desde que esta organização iniciou, em 2004, um trabalho de avaliação de políticas e de análise de desenvolvimentos na educação terciária em vários países constituem outra sede de informação valiosa sobre experiências e modelos de governança da educação superior usados em diversificados contextos. O relatório final daquela iniciativa (Santiago, et al, 2008), apresentado em Lisboa, a 03 de Abril de 2008, é uma referência essencial para compreender os desenvolvimentos e tendências observadas.

Pode dizer-se, enfim, que a partir dos anos 90 do século passado se assiste a um movimento de reformas e de reestruturação dos sistemas de educação superior na Europa, no sentido de melhor os adaptar às novas necessidades das sociedades, diversificando-se a ofertas, para responder à crescente procura de formação superior. Mais recentemente, sobretudo na década de 2000, assistiu-se a mudanças (Eurydice 2008) no sentido de buscar respostas para a insuficiência de recursos públicos dedicados a este sector, procurando-se, ao mesmo tempo, reforçar a autonomia para responder a crescente preocupação com a independência das instituições públicas de educação superior e a liberdade académica que lhes é intrínseca. As lideranças institucionais confrontam-se, de facto, com maiores exigências de eficácia nos resultados, de eficiência nos seus processos de administração dos recursos financeiros que lhes são atribuídos pelos governos e de prestação pública de contas (accountability) (Pedrosa, 2014).

\section{O Modelo de Governança das Instituições de Educação Superior Adoptado em Portugal}

O actual quadro geral de referência nacional para a governança das instituições em Portugal está consagrado na Constituição, na Lei de Bases do Sistema Educativo e no Regime Jurídico das Instituições de Ensino Superior (RJIES) estabelecido em 2007. Esta legislação introduziu significativas mudanças no modelo de governança e gestão das instituições, que até então se caracterizava por opções de natureza colegial, cabendo à comunidade académica a escolha do/a reitor/a. A nova legislação surgiu após prolongado debate, com variados contributos de estudos por autores nacionais 
e internacionais, que geraram um ambiente favorável à introdução de mudanças (OCDE, 2006; Pedrosa e Queiró 2005; Veiga Simão, 2003; Veiga Simão, Machado dos Santos e Almeida Costa, 2002).

O Conselho Nacional de Educação entendeu que, volvidos 10 anos sobre o estabelecimento daquele novo modelo, se devia promover um estudo sobre a experiência colhida, assinando em Dezembro daquele ano um protocolo coma Universidade de Aveiro para a realização daquele trabalho. A equipa que tive o gosto de coordenar entregou o relatório do trabalho em 2012, de que resultou uma publicação recente do Conselho (CNE, 2013). Analisaremos aqui algumas conclusões desse estudo.

Pode referir-se como síntese das principais transformações introduzidas pelo RJIES que se passou de um modelo colegial, de base interna, com múltiplas sedes de governança institucional, para um modelo em que se atribuem as responsabilidades pela governança estratégica das instituições a um Conselho Geral, de constituição mista, envolvendo membros internos eleitos e membros externos cooptados por aqueles. O Reitor/Presidente assume agora um papel de promotor de uma visão para a instituição e de liderança na execução das políticas, estratégias e planos de acção aprovados pelo Conselho Geral. A este órgão cabe, ainda, acompanhar e analisar criticamente o trabalho executivo do/a Reitor/a (nas Universidades) ou do/a Presidente (nos Institutos Politécnicos), que deve radicar em instrumentos orientadores, estratégias, planos e orçamentos aprovados pelo CG.

A investigação que sustentou o estudo do CNE que se referiu atrás teve por base entrevistas a uma amostra significativa de Presidentes de Conselhos Gerais (12 de Institutos Politécnicos e 14 de Universidades. O estudo permitiu caracterizar os perfis dos membros externos escolhidos para integrar e presidir aos Conselhos Gerais das instituições, bem como analisar os instrumentos de regulação e os modos de funcionamento destes órgãos. Tendo as instituições adoptado distintas composições do CG e opções variadas no que respeita a outras sedes de governança e gestão, procurouse, também, estudar as relações desenvolvidas entre os Conselhos Gerais e as restantes estruturas de governança institucional, enfim, os processos e experiências de trabalho vividos no período de vigência da nova Lei. 
Procurar-se-á, de seguida, apresentar um resumo das conclusões do estudo, focando especialmente as que têm que ver com o modo como o modelo é visto pelos entrevistados.

\subsection{Contextos e Tendências}

A análise dos modelos adoptados nos cinco países europeus estudados e que referimos acima permitiu verificar que, em qualquer deles, a governança interna das universidades assenta em três órgãos: o Conselho, o Senado ou Conselho Académico e o/a Reitor/a ou Reitoria. O Conselho tem normalmente a responsabilidade de aprovar a estratégia institucional e de acompanhar a sua execução. Cabem-lhe ainda responsabilidades na gestão dos recursos, nas relações com os Governos e na prestação de contas ("accountability". Os Senados ou Conselhos Académicos são órgãos colegiais que, além de funções consultivas em assuntos pedagógicos ou de investigação, podem assumir responsabilidades na orientação, estratégia e administração daquelas duas áreas essenciais (casos da Áustria, Dinamarca, Holanda e Inglaterra). O University Collegiate Body das universidades finlandesas tem responsabilidades no controle financeiro, na definição da constituição do Conselho, na escolha e demissão dos seus membros.

O/a reitor/a é, em todos os casos, a sede executiva máxima da instituição. Sendo uma escolha do Conselho, é perante este órgão que responde, apresentando propostas de estratégia, de plano e de orçamento. Estes instrumentos, cuja aprovação é da competência do Conselho, são aplicados pelo reitor, que pode intervir na nomeação da governança intermédia (directores de faculdades, escolas e departamentos), tendo especiais responsabilidades na condução da gestão dos recursos.

O sistema de governança adoptado pelas instituições de natureza politécnica não difere substancialmente do que apresentámos para as universidades, com ajustamentos que se explicam pelas diferenças de missão e pelas relações destas instituições com as regiões em que se inserem e respectivos tecidos empresariais.

O número e o modo de designação dos membros do órgão que designamos por Conselho variam com o país. Os países que estão a usar modelos de governança que resultaram de mudanças na le- 
gislação feitas na década de 2000 partilham a opção por Conselhos de pequena dimensão, aproximando-se mais do modelo usado na Holanda, em que o Conselho de Supervisão tem 5 membros externos nomeados pelo Ministro. Assim, na Áustria os Conselhos são formados por 7 ou 9 membros, todos externos, nas universidades da Dinamarca os Conselhos são formados por 11 membros, com representantes dos corpos da instituição e membros externos (em maioria), enquanto na Finlândia se pode optar entre 7, 9-14 elementos, sendo o número de externos pelo menos $40 \%$ do número total.

Uma característica comum a todos os modelos analisados é a adopção de instâncias de governança colegial para os assuntos pedagógicos e científicos, com forte presença de representantes da comunidade académica, tanto a nível institucional (Senado, Conselho Académico, ...), como a nível de Faculdade ou Escola. Também aqui se registam opções variadas no que diz respeito à dimensão e composição dos órgãos: 12 a 14 membros nas universidades austríacas, com docentes (em maioria), outro pessoal e estudantes; um máximo de 50 membros, com representantes daqueles três grupos, na Finlândia; representação de docentes e estudantes nas instituições dinamarquesas, mas com autonomia para a instituição optar por um Conselho Académico da Instituição ou por Conselhos nas áreas académicas (Faculdades).

Significativo das mudanças observadas na Europa é o desenvolvimento de processos de contratualização e os acordos sobre metas e desempenho celebrados entre universidades e governos, observados na Áustria, na Dinamarca e na Finlândia, a atenção dada às condições de autogoverno, com autonomia institucional reforçada e adequados sistemas de garantia de qualidade e de prestação pública de contas.

\subsection{Mudanças Observadas em Portugal}

Em Portugal, a governança da rede e das instituições de educação superior mereceu grande atenção dos variados grupos de interessados, na primeira década deste século. A aprovação do Regime Jurídico das Instituições de Ensino Superior (Lei nº 62/2007, de 10 de Setembro) pode ser vista como mais uma etapa na consolidação da autonomia e do autogoverno das Instituições de Educação Superior, que desde 
a década de 1980 do século XX havia merecido continuada atenção e tradução em legislação.

O período que antecedeu a publicação do Regime Jurídico das Instituições de Ensino Superior (RJIES) foi rico em contribuições para a discussão de matérias relevantes, sendo oportuno referir o papel que o Conselho Nacional de Educação assumiu, estimulado pelo Ministro responsável pela Ciência e Ensino Superior, José Mariano Gago (CNE, 2008) e os estudos solicitados por este responsável político (OCDE, 2006; ENQA, 2007).O estudo da OCDE dedica atenção a importantes questões com impacto na governança do sistema e das instituições. Salienta-se a referência ao crescimento no acesso, em que Portugal regista o maior ritmo de crescimento na frequência ( $6 \%$ ao ano), em comparação com a UE-15 (3\% ao ano), no período de 1975 a 2001. As propostas de reformas apresentadas naquele relatório são também dignas de menção: criação de um Conselho Nacional para a Educação Superior, com responsabilidades no planeamento; rede de educação superior; órgãos de governança institucional e o papel do/a reitor/a; autonomia e qualidade; investigação, inovação e internacionalização; acesso e financiamento. Aponta-se, também neste documento, para se evoluir do modelo colegial em uso, com múltiplas sedes de governança institucional, para uma estrutura de governança em que um Conselho de composição mista (interna e externa) assuma as maiores responsabilidades no governo das instituições

O estudo empírico realizado a solicitação do $\mathrm{CNE}$, como já se referiu, teve na recolha e análise das opiniões dos Presidentes dos Conselhos Gerais a sua principal base empírica. A este trabalho associaram-se audições promovidas pelo CNE a representantes dos principais grupos de interessados. O Relatório Final do Estudo e as intervenções havidas no seminário em que foi apresentado publicamente foram recentemente recolhidos em livro (CNE, 2013).

A representatividade das instituições públicas abrangidas naquele trabalho (foram entrevistados 26 dos 30 Presidentes dos Conselhos Gerais) permite considerar os resultados significativos dos modos de interpretar o RJIES e das experiências colhidas com a sua utilização. A maioria dos presidentes entrevistados valoriza a experiência e revela um empenho claro em contribuir para a boa governança das instituições a que estão associados, entendendo que o Conselho é um órgão com funções de colaboração, consulta 
e reflexão. A competência do Conselho Geral mais referida pelos Presidentes dos Conselhos Gerais é a eleição do/a Reitor/a ou Presidente, mencionando-se as experiências vividas no seu exercício como positivas. A aprovação do orçamento recolhe, também, um expressivo número de referências nas entrevistas, com clara manifestação de insatisfação com as práticas dominantes. De facto, existem referências e perplexidade e desconforto no exercício desta função, admitindo-se a supressão desta competência do Conselho, se não forem profundamente alteradas as condições proporcionadas às instituições para prepararem e validarem internamente as respectivas propostas orçamentais anuais. A aprovação do plano estratégico é a terceira competência mais referida nas entrevistas, com registos de diversas práticas no processo de elaboração do documento. Parece, pois, justificar-se uma aprofundada análise das interpretações da missão do Conselho Geral, envolvendo as comunidades académicas e personalidades com experiência colhida neste primeiro ciclo do RJIES. As competências do órgão estão expressas no artigo $82^{\circ}$ do RJIES, onde se atribui ao Conselho Geral a responsabilidade pela legitimação do mandato do Reitor/Presidente e dos principais instrumentos de orientação da governança estratégica da instituição.

A constituição e dimensões adoptadas pelos Conselhos Gerais devem também merecer atenção, a partir das seguintes observações:

- Existe grande variação nos números de membros dos Conselhos Gerais adoptados: uma instituição opta pelo número mínimo que a lei prevê, 15; uma escolheu o número máximo, 35; 15 instituições têm entre 19 e 25 elementos no CG.

- Um número significativo de Presidentes dos CG com maior número de elementos considera que a sua dimensão deve ser menor e que os membros externos devem estar em maioria.

- As dimensões adoptadas não reflectem com clareza o que a lei estabelece no que diz respeito à relação entre as dimensões do Conselho e as das Instituições: O conselho geral é composto por 15 a 35 membros, conforme a dimensão de cada instituição e o número das suas escolas e unidades orgânicas de investigação (artigo $81^{\circ}$ do RJIES). 
A escolha dos membros externos é feita por cooptação da maioria absoluta dos membros representantes dos professores, investigadores e representantes dos estudantes, "com base em propostas fundamentadas subscritas por, pelo menos, um terço daqueles membros". A escolha dos membros internos resulta de eleição por lista. Qualquer destes processos de escolha é merecedor de reparos dos Presidentes dos Conselhos Gerais, existindo sérias reticências sobre a elegibilidade de directores de faculdades, escolas e departamentos, ou de titulares de outros órgãos, por poder gerar conflitos de interesses.

Os modos de organização interna e de funcionamento dos Conselhos são merecedores de referências com significado e que poderão servir de inspiração a ajustamentos futuros. Parecendo observar-se boas relações e abertura à cooperação entre membros externos e internos, aponta-se a necessidade de desenvolver e explorar vias de comunicação com outras sedes de governança interna. A estruturação do Conselho em comissões especializadas não é prática generalizada e registam-se indicações de que, em alguns casos, não é prestada a atenção devida às condições exigidas para um bom funcionamento de um órgão com o estatuto e autonomia do CG (secretariado, orçamento, espaço próprio).

O/a Reitor/a e Presidente são vistos como a face pública das instituições, adoptando-se frequentemente modos de relacionamento em que assuntos mais relevantes das instituições são analisados de forma conjunta pelos Presidentes dos Conselhos Gerais e Reitores/Presidentes, independentemente do grau de profundidade da relação existente entre os dois órgãos. A análise dos perfis dos Presidentes conduziu à identificação de três opções predominantes: académico (50\%), empresarial (33\%) e serviço público $(13 \%)$. A generalidade dos Presidentes dos Conselhos Gerais refere que a relação estabelecida com os Reitores/Presidentes é muito positiva e cooperante.

Em síntese, dir-se-á que, tratando-se de um modelo de governança novo no País, não surpreende que se enunciem dúvidas sobre algumas interpretações da divisão de competências entre Conselho Geral e Reitor/Presidente. As relativas à natureza do órgão, nomeadamente, ser sede de deliberação, controle e ou supervisão, as perplexidades geradas com a aprovação do orçamento e do plano estratégico podem eleger-se como focos prioritários de análise e 
discussão nas instituições. De facto o estudo mostrou que o modelo de governança das instituições de educação superior, instituído em Portugal em 2007, tem vindo a ser aplicado em moldes que os Presidentes dos Conselhos Gerais avaliam positivamente. As questões suscitadas, os problemas identificados e as mudanças preconizadas podem encontrar respostas em adequadas alterações nos estatutos, na regulamentação interna e nas práticas adoptadas. Na verdade, existe amplo campo de acção a ensaiar, usando potencialidades ainda não exploradas e assumindo com inteligência as competências previstas para o órgão Conselho Geral e as relações que deve estabelecer com outras sedes de governança das instituições. 


\section{Referências}

Aarrevaara, T., Dobson, I. R. and Elander, C. (2009). Brave New World: Higher Education Reform in Finlanf. Higher Education and Management Policy, 21(2), 1-18.

Amaral, A., Jones, G. A. and Karseth, B., (eds) (2002). Governing Higher Education: National Perspectives on Institutional Governance. Kluwer: Dordrecht, Holanda.

Arroteia, J. (2002). Ensino Superior Politécnico em Portugal. Universidade de Aveiro: Aveiro, Portugal.

Browne L. (2010). Browne-report: Securing a sustainable Future for Higher Education - an Independent Review of the HE Funding and Student Finance, London. Disponível em http://independent.gov.uk/browne-report .

Carney, S. (2006). University Governance in Denmark: from democracy to accountability?

European Educational Research Journal, Volume 5, Number 3\&4.

Christensen, T. (2011). University Governance reforms: potential problems of more autonomy? HighEduc, 62: 503-517.

Clark, B. R, (1998). Creating Intrepreneurial Universities: Organizational Pathways for transformation. Elsevier Science: Oxford, UK.

CNE - Conselho Nacional de Educação (2008), Politicas de Ensino Superior - Quatro temas em debate, Lisboa.

CUC - Committee of University Chairs (2009), Guide for Members of Higher Education Governing Bodies in the UK. HEFCE: Bristol, UK.

Danish Ministry of Science, Technology and Innovation (2007), Ministerial Order concerning the Act on Universities (the University Act) - Consolidation Act no. 1368 of 7 December. Copenhaga, Dinamarca.

Danish Universities and Property Agency (2009), The University Evaluation 2009 -Evaluation Report. Danish Ministry of Science, Technology and Innovation: Copenhaga, Dinamarca.

Davies, J., Weko, T. Kim, L. and Thulstrup, E. L. (2009). OECD reviews of Tertiary Education: Finland. OECD: Paris, França. 
EURYBASE (2009). Organisation of the education system in The Netherlands, 2008/2009.

EURYBASE (2010). Organisation of the education system in the Kingdom - England, Wales and Northern Ireland, 2009/2010.

EURYBASE (2009). The education system in Austria, 2008/2009.

EURYBASE (2010). Organisation of the education system in Denmark, 2009/2010.

EURYBASE (2010). Organisation of the education system in Finland, 2009/2010.

EURYDICE (2008). Higher Education Governance in Europe. Policies, structures, funding and academic staff. Brussels: Eurydice.

Eurydice (2012). The European Higher Education Area in 2012: Bologna Process Implementation Report.Eurydice: Bruxelas, Bélgica.

Edwards, E. G. (1982). Higher Education for Everyone. Russel Press: Nothingham, UK.

ENQA (2006), Quality Assurance of Higher Education in Portugal - An Assessment of the Existing System and Recommendations for a Future System. Helsínquia, Finlandia,

Fielden, J. (2008). Global Trends in University Governance, The World Bank Education Working Papers Series, n. 9, March 2008.

Finish Ministry of Education and Culture (2009), Universities Act 558/2009 (As amended up to 315 /2011). Helsínquia, Finlândia.

Graham, G. (2002). University: The Recovery of an Idea, $2^{\text {nd }}$. ed.. Imprint Academic: Exeter, UK.

Huang, F. (2012). Higher education from massification to universal access: a perspective from Japan. High Educ. 63:257-270.

Kerr, C. (2001). The Uses of the University. Harvard University Press: Cambridge, USA.

Marginson, S., Weko, T. Channon, N. Lukkonen, T. and Oberg, J. (2008). OECD reviews of Tertiary Education: Netherlands. OECD: Paris, França. 
Neves, C. E. B. (2003). Diversificação do sistema de educação terciária: um desafio para o Brasil Tempo Soc. vol.15 no.1 São Paulo Apr. 2003, 21-44.

OCDE - Organização para a Cooperação e Desenvolvimento Económico (2006). Reviews of National Policies for Education - Tertiary Education in Portugal. Paris, França.

Pedrosa, J. e Queiró J. F. (2005), Governar a Universidade portuguesa: missão, organização, funcionamento e autonomia. Fundação Calouste Gulbenkian: Lisboa, Portugal.

Pedrosa, J., Santos, Hália Costa, Mano, Margarida e Gaspar, Teresa (2013), Novo Modelo de Governança e Gestão das Instituições de Ensino Superior em Portugal - Análise dos Usos do Modelo em Instituições Públicas. In: Autonomia e Governança das Instituições de Ensino Superior, p. 9-151. Conselho Nacional de Educação: Lisboa, Portugal.

Pedrosa, J. (2014), Autonomy and Accountability in University Governance. In: Bergan, S., Egron_Polak, E., Kohler, J. and Purser, L. (eds.) Leadership and Governance in Higher Education, Handbook for Decision-makers and Administrators, Supplement volume № 01.Berlin: Raabe Academic Publishers.Readings, B. (2003). A Universidade em Ruinas. Editora Angelus Novus: Coimbra, Portugal

Reimer, D. and Jacob, M. (2011). Differentiation in Higher Education and its Consequences for Social Inequality: introduction to a special issue. High Educ. 61: 223-227.

Roska, J. (2011). Differentiation and work: inequality and degree attainment in US higher education. High Educ. 61: 293-308

Santiago, P., Tremblay, K., Basri, E. and Arnal, E. (2008), Tertiary Education for the Knowledge Society. Volume 1. Special Features: Governance, Funding, Quality. OCDE: Paris, França.

Santiago, P., Tremblay, K., Basri, E. and Arnal, E. (2008), Tertiary Education for the Knowledge Society, Volume 2. Special Features: Equity, Innovation, Labour Market, Internationalisation. OCDE: Paris, França.

Seabra Santos, F. e Almeida Filho, N. (2012). Quarta Missão da Universidade:

Internacionalização Universitária na Sociedade do Conhecimento. Imprensa da Universidade de Coimbra: Coimbra, Portugal. 
Shattock, M. (ed.), (1996). The Creation of a University System. Backwell: Oxford, UK

Schindler, S. and Reimer, D. (2011). Differentiation and social selection in German Higher Education. High Educ. 61: 261-271.

Sousa Santos, B. e Almeida Filho, N. (2009). A Universidade no Século XXI: Para uma Uma Universidade Nova. Edições Almedina: Coimbra, Portugal.

Stevens, R. (2004). University to Uni: The politics of Higher Education in England since 1944. Politico's: Londres, UK.

Teixeira, P. Rocha, U. Biscaia, R. and Cardoso, M. F. (2012). Competition and diversity in Higher Education: an empirical approach to specialization patterns of Portuguese institutions. High Educ, 63: 337-352.

Torgal, L. R. (2002). A Universidade de Coimbra: Nota Histórica. Em: Pereira, I. M. B. (cooord.), A Universidade de Coimbra. Universidade de Coimbra: Coimbra, Portugal.

Varghese, N. and Martin. M. (2013). Governance Reforms and University Autonomy in Asia. International Institute for University Reform and UNESCO: Paris, França.

Veiga Simão, J., Machado Santos, S. e Almeida Costa, A. (2002). Ensino Superior: Uma Visão Para a Próxima Década. Lisboa: Gradiva.

Veiga Simão, J. (2003). Modernização do Ensino Superior - da Ruptura à Excelência. Fundação das Universidades Portuguesas: Coimbra, Portugal.

Wadsack, I. and Kasparovsky, H, (2004). Higher Education in Austria, $2^{\text {nd }}$ ed.. Federal Ministry of Education, Science and Culture: Viena, Austria. 